\title{
La mítica perversión en Lope de Aguirre: una aproximación psicoanalítica de la Relación de la jornada de Omagua y el Dorado de Pedrarias de Almesto
}

\section{The mythical perversion in Lope de Aguirre: a psychoanalytic approach of Relación de la Jornada de Omagua y el Dorado by Pedrarias de Almesto}

\section{ANÍBAL CARRASCO RODRÍGUEZ ALEJANDRO VARAS ALVARADO}

\author{
Universidad de Playa Ancha de Ciencias de la Educación. \\ Correo electrónico: anibal_acr@hotmail.com \\ Pontificia Universidad Católica de Valparaíso. \\ alejandro.v.alvarado@gmail.com
}

El presente artículo busca crear una primera aproximación psicoanalítica al relato de la expedición de conquista que protagoniza Lope de Aguirre, enfocando particularmente su análisis en la Relación de la jornada de Omagua y el Dorado de Pedrarias de Almesto (1562), recientemente publicada por Álvaro Baraibar (2012). Proponemos leer el relato dando énfasis a los aspectos relacionados con la transgresión de las diversas instancias de la Ley, lo cual nos llevará a identificar tres nudos psicoanalíticos: las resonancias míticas de la jornada, su estructuración perversa y el rol de testigo cómplice en la figura del propio Almesto. Lo anterior nos ayudará a establecer una hipótesis sobre la amplia y contradictoria recepción que ha tenido la jornada a más de 400 años y, además, nos permitirá vincular este relato mítico con las raíces coloniales de América Latina, cuestionando, incluso, algunos aspectos de la teoría psicoanalítica.

Palabras clave: Lope de Aguirre, mito, perversión, psicoanálisis, literatura colonial.

The following article proposes a preliminary approach to the account of the expedition carried out by Lope de Aguirre from a psychoanalytic perspective, mainly focusing in the recently published manuscript by Álvaro Baraibar (2012) Relación de la Jornada de Omagua y el Dorado by Pedrarias de Almesto (1562). We propose read the account stressing the aspects related to "the law" and its many instances of transgressions, which will lead us to identify three psychoanalytic knots: the mythical resonances of the expedition, its perverse structuring and the accomplice witness' role of Almesto himself. This will help us to establish a hypothesis on the wide-reaching and contradictory 
reception that this expedition has had for more than 400 years. In addition, it will help us connect this mythical account to the colonial roots of Latin America, even questioning some aspects of psychoanalytic theory.

Key words: Lope de Aguirre, myth, perversion, psychoanalysis, colonial literature.

\section{INTRODUCCIÓN}

Lo acontecido en la jornada de Omagua y el Dorado ${ }^{1}$ (1560), donde Lope de Aguirre termina como protagonista, tiene una importancia fundamental para los estudios coloniales ya que permite cuestionar la situación de América en el siglo XVI (Baraibar 2011: 188). La expedición terminó siendo una forma de encauzar el malestar de los conquistadores en contra del reparto injusto de tierras y bienes por parte de la Corona, a quienes habían dado su vida luchando y sometiendo a los aborígenes (Galster 2011: 68). Su relevancia está dada por el grado de ambición que tuvo la rebelión contra la monarquía española, cuyos participantes fueron los primeros en llegar a desnaturalizarse de España en la historia de América, anticipándose en 250 ańos a los movimientos independentistas (Galster 2011: 67). Si bien no fue el único intento de rebelión contra la Corona, su particularidad reside en ser una especie de consolidación y profundización de las rebeliones anteriores (Galster 2011: 61), una suerte de reivindicación de lo que ocurría en las indias occidentales (Baraibar 2011: 197).

Por otra parte, su relevancia queda de manifiesto cuando se examina su recepción a más de 400 años de haber ocurrido. Ésta da cuenta de múltiples apropiaciones marcadas históricamente por diversos matices políticos y estéticos ${ }^{2}$. En este devenir histórico-social la figura de Lope de Aguirre se ha metamorfoseado en torno a dos polos (Galster 2011: 2; Armas 1988: 155): como un loco demonizado (en especial por gente de la época) y un precursor de los movimientos de emancipación independentista de América (Galster 2011: 2). Dicha polaridad no agota las variaciones en torno de Aguirre: "no sólo es loco, demonio y libertador sino también caudillo, dictador, encarnación de la esencia española, comunero, rojo, bolchevique, anarquista, representante de una utopía retrógrada, Las Casas o anti-Las Casas" (Galster 2011: 2-3). Esta ambigüedad será esencial para la interpretación psicoanalítica del texto del Almesto, en términos de su estructuración perversa.

\footnotetext{
${ }^{1}$ El Dorado, como sinónimo de ciudad o reino lleno de riquezas, aparece como una de las motivaciones que tienen los conquistadores para emprender esta expedición (Baraibar en Almesto 2012: 10). Según Galster, su origen está dado por una leyenda que hablaba de baños rituales en oro por parte del cacique de los Chibchas en la laguna de Guatavita, Bogotá (Galster 2011: 58).

${ }^{2}$ En cuanto a la recepción propiamente estética, podría ser relevante para otros estudios que prosigan esta misma línea de análisis, no sólo considerar los registros escritos de la jornada, sino representaciones artísticas posteriores en la literatura, el cine y el teatro (Galeano 1982; Herzog 1972; Posse 1978; Saura 1988; Otero Silva 1985, entre otros). Para mayor detalle de esta recepción, véase Galster (2011).
} 
La figura de Lope de Aguirre vuelve a tomar actualidad mediante la publicación, por parte de Álvaro Baraibar, de la relación de la Jornada de Omagua y el Dorado de Pedrarias de Almesto (Almesto 2012) ${ }^{3}$. Esta relación no había sido editada, lo que no deja de sorprender en la medida que ha servido de base para gran parte de las reescrituras de lo acontecido en la jornada. Su importancia se ve acrecentada por constituir el testimonio de Pedrarias de Almesto, el escriba que tuvo la participación más prolongada en la expedición (Galster 2011: 23), trabajando para Aguirre (Armas 1988: 143). En particular, este texto enfatiza los aspectos paródicos y burlescos que tuvieron Aguirre y los marañones ${ }^{4}$ con respecto al poder (Baraibar 2011; Diez Torres 2011). Según Baraibar: "el definitivo control de la expedición por Aguirre nos habla de la pérdida de la autoridad, la parodia o representación de una autoridad sin poder y del ejercicio del poder sin la autoridad, por medio del recurso al terror" (Almesto 2012: 33). Atender al modo en que el poder se escenifica en el texto será provechoso para comprender la estructuración perversa del relato. La publicación de aquel texto se torna aún más relevante, considerando que se mantuvo inédito durante el importante estudio de Galster ${ }^{5}$, cuya investigación nos servirá de apoyo para contextualizar y contrastar la recepción de Lope de Aguirre.

Nuestro objetivo es iluminar ciertos pasajes y vínculos de la Jornada de Omagua y el Dorado de Pedrarias de Almesto (Almesto 2012) a través de la teoría psicoanalítica, utilizando ésta última como un prisma que permitirá comprender y relevar de un modo nuevo la relación de la jornada, conectando la particularidad o singularidad de sus personajes y narraciones, con una dimensión estructural de la subjetividad y la cultura colonial. Además,

3 El contexto de producción de este texto está dado por el deseo de Almesto por afirmar su inocencia y lealtad
frente a la Corona: "dejando patente su enemistad incluso con Lope de Aguirre" (Baraibar, en Almesto 2012:
19). Según Baraibar, basado en la propuesta de Martinengo, la relación habría sido escrita con anterioridad a su
declaración de inocencia ante la Audiencia de Bogotá, redacción fechada, según Jos, a finales de 1562. Por otro
lado, como plantea Jos en Baraibar, "son muchos los testimonios que se conservan de la jornada de Omagua y
Dorado como consecuencia de la necesidad de algunos de los supervivientes de demostrar su lealtad a la corona
y explicar el papel por ellos desempeñado en la expedición" (Baraibar, en Almesto 2012: 16). Esto explica en
Almesto la redacción de dos relaciones; mientras la primera es aquella editada por Baraibar y es la que analizamos
aquí, la segunda es una reescritura de la primera, que se apropia de la relación de Francisco de Vásquez, de mayor
envergadura y detalle, para remarcar su inocencia y su rol en la expedición (Baraibar, en Almesto 2012: 18). De
hecho, la segunda relación de Almesto se pensó que no era más que una versión más completa y detallada de
la Vásquez, razón por la cual haya sido publicada seńalando a éste último como su autor (Baraibar, en Almesto
2012: 20). Es todo esto lo que hace relevante el análisis de la primera relación debido a su influencia en la
segunda: "se trata de un caso especialmente interesante de apropiación y reescritura en el contexto de las crónicas
de Indias a finales del siglo xvi" (Baraibar, en Almesto 2012: 20). Además, Baraibar señala que en este primer
escrito se narran con lujo de detalles escenas de exceso, parodia y sátira frente al poder, cuestión excepcional en
relación a otros escritos de la época (Baraibar, en Almesto 2012: 34). Para un acercamiento más detallado del rol
de la escritura como rito de salvación véase Leal (2010).
4 Es el nombre que Lope de Aguirre acuñó para sus soldados. El nombre deriva del río Marańón por el cual
hicieron su trayecto hasta el Amazonas, para luego salir hacia Atlántico.

${ }^{5}$ Ingrid Galster realiza una investigación exhaustiva desde el período colonial hasta el siglo XX (Galster 2011). 
pondremos un pie en otros textos que narran la jornada para ampliar algunas posibilidades de análisis. Finalmente, al tomar el relato de Aguirre como un mito de la perversión colonial, tensionaremos la propia teoría psicoanalítica y la hegemonía del mito edípico, relevando la especificidad de la matriz colonial que subyace en las resonancias míticas de la jornada de Omagua y el Dorado.

El psicoanálisis no sólo ha centrado sus esfuerzos en la práctica clínica, sino que desde sus inicios se ha ido construyendo con un pie en lo social, como el estudio de la religión y otras dimensiones humanas ${ }^{6}$. Como Freud ya señala: "desde el comienzo mismo la psicología individual es simultáneamente psicología social en este sentido más lato, pero enteramente legítimo" (Freud 1992: 67).

En el abordaje de lo social el psicoanálisis se ha servido de la literatura y de la estética, desde allí ha elaborado teóricamente elementos necesarios para su praxis clínica7. El mito de Edipo es un caso ejemplar de cómo un elemento literario-mítico permite abrir un campo teórico, articulando lo individual con lo social. A modo de ejemplo cabe destacar lo que Freud realizó con su recreación artística del Moisés de Miguel Ángel (1913) y el concepto de lo ominoso a través del cuento de E. T. A. Hoffmann (1919) ${ }^{9}$. En este último texto, Freud puntualiza que el psicoanalista "aquí y allí sucede que deba interesarse por un ámbito determinado de la estética, pero en tal caso suele tratarse de uno marginal, descuidado por la bibliografía especializada en la materia." (Freud 1986b: 219). De este modo, la relación entre el psicoanálisis y la literatura ha sido bidireccional, en la medida que el primero ha sido tensionado, ampliado y reformulado a partir de esta última.

Si bien ha habido diferentes aproximaciones a la jornada de Omagua y el Dorado, no hemos encontrado una aproximación psicoanalítica de la figura de Lope de Aguirre ni de la jornada. Sólo hemos encontrado dos miradas que se acercan a esta comprensión. Se trata del estudio psiquiátrico de Ramón Pardal (1934) y el estudio histórico-psicológico de Lastres y Seguín (1942). Ambas aproximaciones se centran casi exclusivamente en la figura de Lope de Aguirre. El primero, trata de una aproximación que, mediante el uso de la nosografía psiquiátrica de la época, termina menospreciando el carácter reivindicativo en pos de una patologización, acercándose a una defensa de la sumisión (Galster 2011:351). El segundo, es un trabajo más complejo en cuyas conclusiones hay una manifiesta contradicción, ya que caracteriza la figura de Aguirre como guerrero representativo de la época y al mismo

\footnotetext{
${ }^{6}$ Ejemplos de aquello son las obras de carácter antropológico de Freud, tales como Tótem y tabú (1913), Psicología de las masas y análisis del yo (1921), El porvenir de una ilusión (1927), El malestar en la cultura (1930), Moisés y la religión monoteísta (1939). Así también las obras de pensadores influenciados por el psicoanálisis tales como Enrique Pichon-Rivière, Erich Fromm, Herbert Marcuse, Louis Althusser, Cornelius Castoriadis, Ernesto Laclau o Slavoj Žižek, entre otros.

${ }^{7}$ Véanse algunos ejemplos tales como Freud 1992b; Bettelheim 1977; Lacan 2005: 5-55; Laclau 2000: 257-267; Butler, Laclau \& Žižek 2011: 215-261.

${ }^{8}$ Véase “El Moisés de Miguel Ángel” (1914) en Freud 1986a.

${ }^{9}$ Véase "Lo ominoso" (1919) en Freud 1986b.
} 
tiempo como encarnación de una personalidad anormal. Dicha conclusión no es rigurosa ni explicativa (Galster 2011: 367-368). Persiste de esta manera la 'ambigüedad' resultante de los diversos enfoques. A diferencia de los estudios anteriormente señalados, aquí nos interesa una aproximación al texto de Almesto y a la variedad de personajes dentro de la relación. No sólo nos centraremos en Lope de Aguirre, sino en cómo el resto de la expedición guarda una estrecha relación con la estructuración perversa; orientándonos más allá de un enfoque centrado en la verificabilidad histórica de sus hechos y personajes, colocando atención más bien a la construcción ficcional o mítica de la misma.

Ahora bien, con respecto a esto último, se vuelve necesario separar aguas; queremos dejar en claro que lo acontecido en la jornada de Omagua y el Dorado se ha interpretado y recreado con un pie en la historiografía y otro en la ficción. En la difuminación de estos dos campos, el lector muchas veces ha quedado al desamparo, ya que se le ofrece una mezcla de verdad y verosimilitud: "la imaginación y el recurso a procedimientos literarios pueden favorecer el conocimiento siempre que no encubran la dimensión histórica" (Galster 2011: 758). Para evitar esta problemática, articulamos ambas dimensiones en torno al concepto de mito. Éste nos permitirá interpretar las resonancias míticas presentes en el texto de Almesto que se vinculan ineludiblemente con algunos aspectos de nuestra historia o pasado colonial. Esta interpretación será de carácter psicoanalítico y recurrirá a la perversión como una lógica estructurante, explicando, desde allí, la inmensa y contradictoria recepción que el texto ha tenido.

De este modo, en este escrito intentaremos establecer un vínculo entre el contexto de producción del texto de Almesto y la inmensa recepción de lo acontecido en la Jornada de Omagua y el Dorado. Dicho vínculo nos permite señalar que las reescrituras y reapropiaciones (a más de 500 años) nos hablan de un contenido que nos vuelve a interpelar, trascendiendo el contexto histórico de su producción. Desde ahí se torna lícito pensar en las resonancias de una dimensión ligada a lo universal, ligada a aspectos primordiales de la subjetividad y colectividad humana. Esto último puede apreciarse tanto en la producción como en la recepción de la relación, toda vez que consideremos aquel relato desde la figura de lo mítico ${ }^{10}$.

\footnotetext{
${ }^{10} \mathrm{La}$ articulación entre, por un lado, la dimensión histórica y contingente de la producción de un texto y, por otro, los efectos o resonancias que éste genera en su contexto de recepción, puede ser comprendida desde la categoría de lo universal, entendida no como una esencia trascendente, sino más bien, desde el psicoanálisis y la filosofía, como una dimensión estructural pero elusiva tanto de la subjetividad como de las colectividades humanas. En este sentido, la categoría de mito ofrece elementos que permiten articular tanto lo histórico con lo ficcional, lo singular de una sociedad con los aspectos generales de la cultura. La operación que realizan los mitos, es analogable a la función que desempeña la ideología según Žižek. La ideología "es una construcción de la fantasía que funge de soporte a nuestra 'realidad': una 'ilusión' que estructura nuestras relaciones sociales efectivas, reales y por ello encubre un núcleo insoportable, real, imposible” (Žižek 2016: 76). Es en ese sentido de estructuración y soporte donde lo universal aparece más bien como una construcción humana. Por tanto, el mito aquí no refiere tanto o solamente a un supuesto texto original sino más bien a la recreación o reactualización de un pasado. Es por ello que adquiere importancia la inmensa recepción de la Jornada: "Hay más verdad en la eficacia posterior de un texto, en la serie de sus subsiguientes lecturas, que en su sentido supuestamente original"
} 


\section{LAS RESONANCIAS MÍTICAS DE LA JORNADA}

La búsqueda de la ciudad del Dorado, el trágico final de la jornada y la enorme recepción, permiten hablar de las resonancias míticas de la expedición, cuestión que ha sido abordada extensamente (Marcus 1968; Armas 1988; Triviños 1991; Neira, Fierro \& Viveros 2006), pero sin el matiz que el psicoanálisis le confiere. Esta rebelión se puede comprender como un mito, ya que "cuenta una historia sagrada; relata un acontecimiento que ha tenido lugar en el tiempo primordial, el tiempo fabuloso de los 'comienzos” (Eliade 1991: 7). La jornada se imbrica en los primeros cien años de la conquista, donde ésta aún no se consolidaba. Diversos territorios se mantenían desconocidos, otros aislados y, como en el caso del pueblo mapuche, muchos permanecían bajo dominio aborigen. Debido a esto, las expediciones, como la de Aguirre, delinearon la actual configuración de América Latina. Por ello, se trata de nuestros tiempos míticos, en donde se enmarañan simbólicamente nuestras sangrientas raíces.

Este relato en su faz mítica, tiene su fuerza, su repetición y reelaboración, en tanto escenifica elementos constitutivos de la cultura, como los pulsionales, inconscientes y colectivos, que vuelven a aparecer en los cuentos y también en los mitos (Bettelheim 1977: 41). Desde el psicoanálisis, podemos afirmar que la lo acontecido en la Jornada de Omagua y el Dorado tiene algunas resonancias propias de un mito y, como tal, nos lleva al punto donde la historia humana colinda con la aporía y donde sólo es posible una elaboración: "dilucidar el estado originario es siempre un asunto de construcción" (Freud 1986a: 106). ¿Cómo debe ser esa construcción? No hay una respuesta definitiva, creemos que esta construcción se "vuelve una recreación poiética. No es lo mismo que el acceso a una obra de arte, pero se sitúa mucho más por ese lado que por el lado de la comprensión de la necesidad de las etapas de una demostración matemática” (Castoriadis 2004: 33).

A continuación, nos dedicaremos a dar cuenta de diversos personajes en su función simbólica, además, mencionaremos algunos elementos trágicos presentes en el texto de Almesto. Lo anterior, será vinculado con el mito de la horda primordial que trabaja Freud en Tótem y Tabú (1913), el cual tiene variadas similitudes con la expedición de Aguirre.

En general, desde la tragedia griega, un relato trágico ha versado sobre la "sublevación contra una autoridad divina o humana [...], el coro acompañaba al héroe con sus sentimientos de simpatía, procuraba disuadirlo, alertarlo, moderarlo" (Freud 1986a: 157) ${ }^{11}$.

En este mito trágico la sublevación es fundamental, ésta se manifiesta en el desafío y la transgresión a las diversas instancias que encarnan la Ley. La misma expedición de conquista se trata de una transgresión ${ }^{12}$.

(Žižek 2016: 272). En el mismo sentido se puede comprender lo que Galster ya plantea respecto a la recepción de Lope de Aguirre: "por la necesidad de la transferencia se tiende a universalizar lo particular, se transforma la historia en literatura” (Galster 2011: 755).

${ }^{11}$ La misma relación podemos establecer entre Aguirre y sus marańones, como héroe trágico y el coro que busca su propia salvación a través del uso de la figura del héroe.

${ }^{12}$ Tal como señala Baraibar, se trataría de una excepción frente a las leyes "después de que [las jornadas de 
Desde el comienzo de la expedición, corrió el rumor de que ésta tenía por objetivo alzarse contra el rey Felipe II, por lo mal que traía estas regiones; otra de las motivaciones que en cierta medida le dieron impulso fue el relato de la mítica ciudad del Dorado (Baraibar en Almesto 2012: 10). Ambas motivaciones dan un aspecto doblemente trágico, ya que no se logra encontrar las riquezas que míticamente se narraban y, por otro lado, la misma sublevación contra el rey termina en una catástrofe o, como dice Baraibar: "Aguirre va dirigiendo las acciones de los rebeldes en una suerte de huida hacia adelante sin posibilidad alguna de perdón o salvación por parte del monarca" (Almesto 2012: 14). Esa huida hacia adelante es también una manera de remarcar el empuje que tuvo la rebelión para transgredir de forma progresiva cualquier instancia que encarnaba la Ley.

La serie de transgresiones que realizan Aguirre y los marañones se puede leer tomando en consideración el mito de la horda primordial. Este mito darwiniano reelaborado por Freud, es una hipótesis mítica del nacimiento de las instituciones sociales, tal como el mito de Edipo nos permite comprender la encrucijada que constituye la subjetividad humana. Nos permitimos citar en extenso el asesinato del padre primordial:

Unidos osaron hacer y llevaron a cabo lo que individualmente les habría sido imposible. (Quizás un progreso cultural, el manejo de un arma nueva, les había dado el sentimiento de su superioridad). Que devoraran al muerto era cosa natural para unos salvajes caníbales. El violento padre primordial era por cierto el arquetipo envidiado y temido de cada uno de los miembros de la banda de hermanos. Y ahora, en el acto de la devoración, consumaban la identificación con él, cada uno se apropiaba de una parte de su fuerza. El banquete totémico, acaso la primera fiesta de la humanidad, sería la repetición y celebración recordatoria de aquella hazaña memorable (Freud 1986a: 143-144).

La primera transgresión en la jornada es el asesinato del gobernador Pedro de Orsúa que, como representante del monarca, ocupa simbólicamente el lugar del padre primordial. Dicho acto es cometido por gran parte de los soldados quienes, frente a la ineficacia de Orsúa para hacer frente a los desafíos que les plantea la travesía por el río Marañón y por estar más preocupado de doña Inés de Atienza, entran a su tienda y lo matan a estocadas, uno a uno, repartiendo el acto criminal entre varios soldados, mientras Aguirre espera en la puerta del lugar (Almesto 2012: 74). De esta forma realizan colectivamente algo que les sería imposible de forma individual.

Luego del acto, todos, como señala Baraibar, tomando la relación de Francisco Vásquez (1562), se comprometieron a firmar un documento en el cual trataban a Orsúa como un traidor. Este recurso burocrático les permitía no ser condenados por el poder monárquico: "Todo ello quedó recogido en una información que debía ser firmada por todos". En este documento Aguirre firma como "el traidor" (Baraibar en Almesto 2012: 14).

conquista] hubieran sido prohibidas ya en 1550" (en Almesto 2012: 9). 
Primer vínculo entre la escritura y la transgresión, el cual se mantendrá más adelante con respecto al propio Pedrarias de Almesto. También constituye una huella de la transgresión y una suerte de aviso de la imposibilidad de retroceder en la rebelión.

En el asesinato a Orsúa la escritura opera como un mecanismo que permite repartir y eximir la culpa. La escritura es el artificio que permite delegar la responsabilidad creando un vínculo ético entre los soldados (hermanos), quienes quedan en una relativa paz. Una vez asesinado el gobernador salieron del lugar vociferando: " $i V i v a$ el rey!, caballeros, que muerto es el tirano"' (Almesto 2012: 74).

En relación al Padre (Orsúa), ya venían acumulando odio por el egoísmo, el poder y disfrute al que se entregaba con doña Inés. Recordemos los sentimientos que generaba aquel padre mítico: "Odiaban a ese padre que tan gran obstáculo significaba para su necesidad de poder y sus exigencias sexuales, pero también lo amaban y admiraban" (Freud 1986a: 145). Esa admiración es el núcleo de donde emana la culpa de los soldados, no es casual que se emborrachen, entendiendo que han asesinado al representante del monarca. Así, la inhibición que genera la fiesta y el vino vuelve a generar un paréntesis a la ley que impone la realidad. Los excesos en la celebración, la repartición de las ropas y los enseres del gobernador, son resonancias del banquete totémico que viene a re-escenificar el parricidio: "pedían muchos otros los sayos de terciopelo, las calzas y la demás ropa" (Almesto 2012: 76). En este banquete, todos comen una parte del padre, asimilando así las características envidiadas. El banquete totémico tiene el propósito inconsciente de asimilar parte de la fuerza del padre asesinado, aumentando su identificación con él, pero también ese exceso festivo está vinculado con la ruptura de la Ley:

Una fiesta es un exceso permitido, más bien obligatorio, la violación solemne de una prohibición. Los hombres no cometen esos excesos porque algún precepto los ponga de talante alegre, sino que el exceso mismo está en la esencia de la fiesta; el talante festivo es producido por la permisión de todo cuanto de ordinario está prohibido (Freud 1986a: 142).

Para Freud esta fiesta, luego del asesinato del padre de la horda, es la primera fiesta de la humanidad, a la cual debemos el nacimiento de todas las organizaciones y limitaciones éticas y religiosas. Se trata de la primera celebración que será la de todos los dioses y reyes que advendrán luego como sustitutos de aquel mítico Padre asesinado (Freud 1986a: 152).

En la crónica de Almesto, luego del asesinato, los soldados se entregan a juegos paródicos, solicitando mercedes a quien instituyeron como "don Fernando de Guzmán, por la gracia de Dios príncipe de Tierra Firme y Mar del Sur y reinos del Pirú y gobernación de Chile y de todas las Indias" (Almesto 2012: 36). Las solicitudes a este nuevo príncipe, si bien constituyen un juego, dan cuenta de la relación tensional, de amor y odio, latente en toda encarnación de la figura del Padre. En todas esas metáforas hay una ambivalencia constitutiva dada por la envidia, el temor y la identificación: "hicieron traer la silla del gobernador y hicieron al don Fernando que se sentase imponiéndole a que mostrase autoridad" (Almesto 
2012: 77). Esto le otorga al poder ese lazo transferencial que siempre se encuentra en disputa. Nótese las palabras del nuevo padre a las peticiones de un soldado en medio de los juegos paródicos: "Por cierto, señor, muy de buena voluntad haré yo eso, y desde agora para ese tiempo yo hago eso por vos, porque a los soldados como vuestra merced, que sé yo que no me han de negar, otras mayores dádivas querría yo darles" (Almesto 2012: 76).

Los hermanos quedan con sus manos manchadas, esa huella deja la puerta abierta para un nuevo asesinato y para la competencia entre los hermanos, en términos de ocupar aquel sitial preciado o, por lo menos, tener un cargo que los acerque a la sombra del Padre:

Y luego empezó entre ellos haber invidias y querer mandar y se comenzaron a matar unos a otros, porque a cabo de otros cuatro días mataron a Miranda, su alguacil mayor, y a un Pero Hernández, que se habían hallado estos dos en matar al gobernador. Estos mataron porque decían que habían sabido que ordenaban motín para matar al don Fernando. Fecho esto anduvieron unos con otros en chismes y tomando sospecha unos de otros y comenzaron a que no se fiaban de sí mismos (Almesto 2012: 79).

La nueva organización de la expedición aún no se asienta y el mismo Aguirre comienza a tener problemas con su cargo como maese de campo ${ }^{13}$. Entra en disputa por él, se defiende frente a Guzmán, señalando que él fue uno de los más involucrados en el asesinato del Gobernador. Tras la disputa, Aguirre intenta seducir y engañar a Guzmán, culpando al soldado que le disputa su cargo como rebelde que busca asesinarlo. El Príncipe acepta que Aguirre mate al soldado. En este punto, comienza el protagonismo de Aguirre como aquel hermano que buscará llenar el espacio vacío del poder, aunque, si tomamos sus palabras, podemos señalar que estuvo plenamente involucrado desde el comienzo en el asesinato de Orsúa (Almesto 2012: 80).

El mito de la horda primordial da una interpretación en torno al paso desde la animalidad hacia el mundo humano. La prohibición de ocupar el lugar del padre mítico asesinado posibilita una estructuración social que pasa del clan a lo familiar. Dicha prohibición instaura el tabú del incesto, es decir, impide que cualquiera de los hermanos pueda controlar al resto del grupo humano para su disfrute. De esta manera, cada hermano tiene la posibilidad de replicar el patriarcado y detentar parte del poder ilimitado de aquél mítico padre. Junto a ello se establece un pacto en donde los hermanos no volverán a ocupar aquel lugar, de esta manera, se instaura la Ley y lo que Lacan denomina el gran Otro, entendido como el entramado simbólico que funda la realidad:

Simplemente el "gran otro" lacaniano, [es] el orden simbólico virtual, la red que estructura nuestra realidad. Esta dimensión del "gran Otro" es la de la alienación constitutiva del sujeto dentro del orden simbólico: el "gran Otro" tira de los hilos, mientras que el sujeto es una expresión del orden simbólico (Žižek 2003: 294).

13 "Tras el gobernador, es el segundo mando de una expedición" (Almesto 2012: 58). 
El mito de la horda primordial nos permite comprender la instauración de la Ley del gran Otro en el relato de la jornada. Además, nos entrega un marco para comprender las continuas pugnas por liderar la expedición. La fiesta y el banquete, tal como ocurren, son una forma en la cual se vuelven a escenificar estos aspectos del pasado mítico de la humanidad. Las transgresiones, desafíos y burlas al poder presentes en la jornada, adquieren sentido a través de la relación del perverso con la Ley, cuestión que pasaremos a examinar a continuación.

\section{LA PERVEVRSIÓN COMO ESTRUCTURA SUBYACENTE EN LA RELACIÓN}

A continuación, exploraremos los posibles vínculos entre la Relación y la perversión, considerando esta última como una de las estructuraciones psíquicas definidas por el psicoanálisis lacaniano. Indagaremos en el relato de Almesto aquellos puntos de anclaje de las principales operatorias perversas, lo cual nos distanciará del lugar que ocupa la neurosis con respecto al padre en el mito freudiano de la horda. Para adentrarnos en la perversión es necesario dar un pequeño rodeo por su definición, la cual ha tenido variadas aproximaciones psicoanalíticas desde la literatura: "Es una estructura altamente compleja, tan sofisticada como plena de intrincaciones como una neurosis. Y, por ejemplo, no es por casualidad que todos nos hemos acercado a la perversión a través del trabajo de escritores" (Miller 2001: 22). No responde a la lógica estructural del perverso asistir a psicoterapia, por ello el psicoanálisis ha tenido que buscar otras fuentes para su comprensión:

ellos no piden análisis. Podemos llamar a esto la inanalizabilidad del perverso, . . . ellos no vienen a vernos para buscar el objeto perdido, así que es de sentido común creer que, de algún modo, lo han encontrado y no tienen nada que esperar del análisis (Miller 2001: 20).

Así, la teoría analítica ha puesto un pie en la literatura para poder pensar aquello que escapa a su praxis. Pero desde el psicoanálisis ¿qué es la perversión? Desde Lacan la perversión se inscribe como una de las tres posibles estructuras psíquicas, junto a neurosis y psicosis. La comprensión de esta estructura nos lleva a retomar el Edipo como encrucijada. De esta forma, la perversión es una de sus posibles salidas, en la que la Ley y el Otro adquieren posiciones específicas con respecto al deseo en otras estructuras.

Según Joel Dor, mientras en la neurosis el sujeto "aceptará de buen o mal grado la imposición de la castración y de la ley sometiéndose, pero a riesgo de desplegar hasta el infinito, una inagotable nostalgia sintomática ante la pérdida" (Dor 1995: 96), en la perversión, los sujetos "sólo aceptarán la incidencia de la castración bajo reserva de transgredirla continuamente" (Dor 1995: 96). Esta posición que por un lado acepta la falta fundante del sujeto, y, por otro lado, la niega, advierte una oscilación o paradoja en la que se inserta el perverso. Por un lado, sabe y acepta silenciosamente que la madre fue 
castrada, y el padre "pasa a ser el agente responsable" (Dor 1995: 102), de una ley injusta que lo confronta ante el horror de la no omnipotencia de aquella; por otro lado, niega fantasmáticamente dicha castración, "considerándose él mismo como sólo y único objeto de deseo que la hace gozar" (Dor 1995: 96). Es esta oscilación entre la aceptación y denegación que caracterizará a la perversión y de la cual podremos dar cuenta en la Relación de Almesto.

Debido a que la función paterna se instituye de manera ambigua, los aspectos superyoicos del sujeto quedan relegados y, por tanto, la Ley queda en una virtualidad. Por ello, el perverso intentará continuamente interpelar o invocar la Ley a través de dos formas: el desafío y la transgresión. En el perverso, como la función paterna queda instituida en una ambigüedad constitutiva, el sujeto acepta sólo "la ley de $s u$ deseo, como la única ley del deseo que él reconoce y no como un deseo que se viera fundado sobre la ley del deseo del otro, que es, inauguralmente, la Ley del padre" (Dor 2000: 63). Por un lado, el perverso queda atrapado en la ley de su deseo; por otro lado, desconoce la ley del Otro como lo que mediatiza el deseo de cada cual. Es decir, el perverso, más que aceptar, $<<$ reniega $>>$ la castración, la pérdida fundante por entrar al lenguaje. Aquello que se pierde en la castración es denominado <<objeto a >>, siendo éste aquel exceso y falta que permite la movilidad del deseo: "el objeto $a$ es lo que cae en el medio, en la intersección del Otro con el sujeto" (Nasio 1992: 131). Así lo señala Miller a propósito de Lacan: "Cuando él califica la operación perversa como retornar el goce al Otro, o sea devolver el objeto $a$ al Otro" (Miller 2001:33).

El punto fundamental de la lógica perversa es la renegación de la castración del Otro. Como dice Lacan: "el perverso se dedica a tapar el agujero en el Otro" (Lacan 2008: 230). Ese <<Otro >> escrito con mayúscula es todo el entramado simbólico que estructura y rige la realidad; es la alteridad que nos constituye pero que, a la vez, no podemos aprehender. Es como si nadásemos en una gran piscina, donde el agua sería el gran Otro.

El sujeto perverso estará siempre ligado a la Ley (o al Padre en su dimensión simbólica) y en cualquier instancia en que ésta se encarne buscará desafiarla y transgredirla, como una forma de verificar y suplementar la presencia del gran Otro, devolviendo el objeto.

A continuación, analizaremos tres operatorias perversas presentes en la Relación. La primera relativa a esta ambigüedad $\mathrm{u}$ oscilación, asociada a sus rasgos desafiantes y transgresores; la segunda, en torno al lugar de lo femenino; $y$ la tercera vinculada a la forma en que el deseo perverso se moviliza en torno al objeto $a^{14}$.

\subsection{Desafio, transgresión y oscilación: Aguirre como 'el perverso tirano'}

Uno de los puntos interesantes de la jornada, siguiendo la lógica perversa, guarda relación con el asesinato a Fernando de Guzmán. El propio príncipe instituido por Aguirre y el resto de los soldados, es asesinado a raíz de su incompetencia. Con Orsúa ya asistimos

\footnotetext{
${ }^{14}$ Para mayor detalle en torno a la estructura perversa en psicoanálisis lacaniano, véase: André 1995; Dor 1995; Dor 2000; Julien 2012; Kristeva 2006; Miller 2001; Pardo 2006; Rostagnotto \& Yesuron 2014; Rostagnotto \& Yesuron 2016; Rostagnotto 2015; Yesuron \& Rostagnotto 2015.
} 
a la muerte del representante de la Corona; con el asesinato de Guzmán es el lugar mismo de la autoridad el que ha sido burlado y transgredido. ¿Cómo se podría leer este pasaje? Uno podría esperar que luego del asesinato del padre (Orsúa) Aguirre hubiese ocupado el lugar del poder, sin embargo, la operación de colocar a un otro (Guzmán) para nuevamente asesinarlo da cuenta que el deseo perverso no apunta al establecimiento de una Ley, de una identificación con el padre, sino más bien a una renegación de la ley, más allá de quien ocupe tal posición. No se trata de eliminar particularmente a Orsúa o a Guzmán: en la perversión "no se trata del objeto sino del Otro" (Lacan 2008: 230).

La forma en que Aguirre transgrede la Ley se manifiesta al comparar las dos expresiones contrapuestas con las que el relato refiere a la figura de Guzmán. Por un lado, Aguirre le otorga a éste el pomposo título de príncipe de "Tierra Firme y Mar del Sur y reinos del Pirú y gobernación de Chile y de todas las Indias" (Almesto 2012: 82-83). Pero, por otro, Almesto expone que Guzmán no es más que un nuevo rey hecho a la medida de Aguirre, "su señor fecho de paja" (Almesto 2012: 88). El primer título mencionado recrea de forma burlesca una nueva ley sólo con el fin de perpetuar su transgresión, lo que Almesto reconoce claramente en la segunda referencia a Guzmán.

Además, Aguirre, al coronar y asesinar a Guzmán, promueve inmediatamente que el resto de los marañones se desnaturalicen del vasallaje español. En esta operación Aguirre transporta el lugar simbólico de la Corona a la expedición, posibilitando la transgresión de lo que en este contexto colonial es una de las encarnaciones supremas del gran Otro. En las cartas dirigidas al Fray Francisco Montecinos y al rey Felipe II, Aguirre recrea esta transgresión. En la primera misiva plantea: "A los leales el Rey los resucitara. Avnque hasta agora no veo ninguno resubcitado. el Rey ni sana heridas ni da Vidas" (Galster 2011: 766); y en la segunda afirma: "Rey ... si no pones remedio en las maldades de esta tierra, que te ha de venir azote del cielo; y esto dígolo por avisarte de la verdad, aunque yo y mis compañeros no queremos ni esperamos de ti nada, ni misericordia" (Galster 2011: 778). En ambos extractos observamos el carácter desafiante, expresado en el simultáneo coronamiento y asesinato metafórico del rey: éste puede inicialmente resucitar vidas y poner remedios, pero inmediatamente es incapaz de todo y de él no se espera ley alguna.

El carácter ambiguo de la transgresión también se expresa en la forma en que Aguirre encara el propósito de la conquista, es decir, encontrar el Dorado. Almesto menciona cómo los marañones, ya más avanzada la expedición, se deshacen de diferentes implementos por orden de Aguirre: "Y el traidor de Aguirre, usando de sus crueldades, mandó que dejásemos todo el servicio que traíamos del Pirú allí" (Almesto 2012: 96). Así como no se trata de ocupar el lugar de gobernador ni de príncipe, tampoco se trata de encontrar el oro ni de enriquecerse:

mandó Aguirre que dejásemos toda nuestra ropa, sino solo lo que llevásemos vestidos y se puso él y su maese de campo al tiempo que embarcaban y lo echaban todo al río. Esto hacía... porque decía que robarían y matarían mejor por quitarlo al que lo tuviese (Almesto 2012: 96). 
Tanto en el asesinato de Guzmán, en las cartas al Rey de España y en el desinterés por la búsqueda de El Dorado, podemos ver no sólo los rasgos del desafío y la transgresión, sino además la estructuración oscilante y paradojal del relato con respecto a la castración. Es esta estructuración la que nos permite dar cuenta del carácter perverso de la Relación.

\subsection{La hija de Aguirre y doña Inés: entre la 'virgen'y la 'puta repugnante'}

En la triada Edípica, la madre del perverso se muestra como fálica, es decir, como aquella que actúa seductoramente, de tal manera que para el sujeto no hay una ley clara que impida la fantasía de una unión sexual: "la llamada seductora y la complicidad libidinal de la madre, asociadas a la complacencia silenciosa del padre" (Dor 2008: 57). Aquí, la función materna viene a obnubilar el lugar del padre encargado de generar la interdicción de la Ley, y con ello, la prohibición del incesto: "La mujer que encarnará a la madre fálica será fantasmatizada como una mujer totalmente idealizada" (Dor 2000: 72). Esta idealización puede fantasearse para el perverso como la mujer virgen sin deseo o como una mujer repelente y abierta al deseo de todos (Dor 2000: 72).

En la Relación esto puede observarse en el vínculo existente entre Aguirre y su hija, quien la acompaña durante toda la jornada. Según Almesto, la hija de Aguirre era lo más preciado para el tirano: "precio más estarme un rato con mi hija que todo lo del mundo porque, aunque mestiza, la quiero mucho" (Almesto 2012: 80). La presencia de la hija de Aguirre durante la jornada dota de un carácter femenino virginal, inocente, infantil, pasivo, incluso hasta sacrosanto a la Relación, en contraste con los hechos iracundos, sangrientos y trágicos narrados. Esto cobra aún más fuerza en la medida que esta mujer es la propia hija de Aguirre: el bien y el mal se encuentran unidos filialmente y es Aguirre mismo quien sostiene esta situación. La transgresión continúa como rasgo característico al final de la jornada, cuando Aguirre, al verse acorralado y frente a su propia muerte inminente, decide asesinar a su hija "porque no quedase por colchón de ruin jente" (Galster 2011: 41). Aguirre intenta dispararle con un arcabuz pero la hija se lo quita, frente a esto Aguirre "comenzole a dar de puñaladas hasta que la mató" (Almesto 2012: 110-111). El carácter puro de la hija se conecta con lo divino en su plegaria ante su padre: "Y la hija abrazóse con él diciéndole: ‘Oh, padre mío, por amor de Dios!” (Almesto 2012: 110). El asesinato de su propia hija converge con la necesidad de sostener el carácter virginal de ésta en la lógica perversa, ya que al mantenerla con vida se hubiese vuelto una "puta repugnante" (Dor 1995: 105).

No obstante, al desaparecer esta mujer fálica, mujer no afecta a la castración, desaparece también el deseo de Aguirre, quien "no procuró de defenderse sino, antes, decía palabras de hombre de poco ánimo: 'Señores, no me matéis'” (Almesto 2012: 111). Almesto, luego de narrar el filicidio, señala que "había él [Aguirre] muerto el género humano", lo cual da cuenta de la extinción de lo humano en Aguirre antes de su asesinato, como si él mismo, al matar a su hija, paralelamente cometiese suicidio, lo que podría ser leído como un desvanecimiento estructural frente a la pérdida de la madre idealizada. Esta especie de suicidio desafía nuevamente la eficacia del asesinato por terceros. Hasta en sus últimas 
palabras Aguirre mantiene el desafío: "le tiraron dos arcabuzazos y al primero que le tiraron dijo el Aguirre: 'Ese no es bueno'” (Almesto 2012: 111).

El contrapunto de la hija de Aguirre lo encontramos en Inés de Atienza, amante de Orsúa, siendo su presencia en la jornada "cosa escandalosa" (Vásquez 1881: 39). Ella es descrita como mujer "moza y muy hermosa", pero "de mala fama y peores mañas", siendo "causa principal de la muerte del Gobernador y nuestra total destruicion" (Vásquez 1881: 11). Inés de Atienza, al ser la mujer del padre, por tanto, mujer en donde la castración es innegable, se transforma en la figura de la puta repugnante, de quien nada se quiere saber, lo cual obliga a Aguirre a asesinarla, al igual que a su hija: "Aguirre comenzó a decir a los que traía consigo: «Hacé lo que sabéis», que era ir a matar a la pobre moza de dońa Inés ${ }^{15} \ldots$ un llamoso la tomó por los cabellos y le dio de puñaladas" (Almesto 2012: 87).

De este modo, tanto en la figura de la hija como en doña Inés, es posible ver las coordenadas en las que el deseo perverso se moviliza frente a lo femenino.

\subsection{El asesinato y la destrucción: vías perversas de devolución de objeto}

Si bien los episodios principales y los protagonistas nos permiten arribar a la estructuración perversa de la jornada, existen detalles narrativos que han sido relegados del análisis tradicional. Dichos aspectos son fundamentales para el trabajo analítico, ya que permiten vislumbrar un cierto reverso que se asoma en tales restos. Dichos detalles son útiles para evidenciar la expresión del objeto $a$, toda vez que éste se muestra como un objeto perdido; aquí adquieren la forma de excepciones, quiebres y objetos específicos que deben ser anulados para suplementar la ley del Otro.

Por ejemplo, en torno a los asesinatos cometidos por Aguirre a diversos marañones, es posible señalar que la mayoría de éstos estaban transgrediendo algún orden dentro de la jornada. Donde el Otro falla, donde el objeto a se muestra, allí asiste Aguirre, dispuesto a tapar la fisura: "mandó dar garrote a un soldado marañón porque lo halló a la sombra de un árbol le dijo que se regalaba mucho y por esto lo mató" (Almesto 2012: 104). El soldado pareciera haber atentado contra el régimen de trabajo-descanso, parte fundante de la organización que sigue la expedición de conquista. Nótese el siguiente caso: "aquel día mató un portugués porque había preguntado que a dónde se ponían las centinelas" (Almesto 2012: 104). Aquí la pregunta también tiene que ver con la forma en que se estructura la jornada. Una vez hubo un marañón que hizo una aseveración precisa: "Mire vuestra merced, que se moja los pies" (Almesto 2012: 103), a lo cual respondió Aguirre con cuchilladas, ordenó darle garrotes y allí murió.

¿Qué hay en las palabras de estos soldados? Una señal de que está fallando lo que los transporta y estructura. Es el mismo Aguirre quien va en auxilio del gran Otro y es él,

\footnotetext{
${ }^{15}$ Sobre dońa Inés es interesante notar los efectos que pudo haber tenido en el relato de la jornada, como agente caótico que moviliza el deseo de muchos participantes en la expedición, esta es la forma en que la escenifica Carlos Saura en la película "El dorado" (1988).
} 
quien va a probar la Ley cuando falla: "un negro de los que venían con Lope de Aguirre topó con un mercader en el monte, que estaba escondido y trájolo delante de Aguirre y luego lo mandó ahorcar porque tenía mal gesto ${ }^{16 "}$ (Almesto 2012: 104). En todos estos casos vemos cómo la perversión persevera suplementando la Ley.

Son muchas las acciones en las cuales podríamos observar una devolución del objeto perdido, sin embargo, hay una que destaca por su comicidad. El vino, que antes sirvió para la fiesta totémica y la ruptura de las prohibiciones, aparece como un objeto $a$ que moviliza al perverso:

Y luego otro día siguiente hizo que se quemasen todos los navíos y que derramasen gran cantidad de vino que había en uno dellos; y había tan buenos soldados, de mucha conciencia, que desfondaban las pipas llenas de vino y poníanlas ellos derechas y metíanse dentro desnudos hasta el pescuezo y después derramábanlo por el suelo y mucha cantidad de botijas que quebraban (Almesto 2012: 104).

El vino es un objeto excepcional, se encuentra en uno solo de estos navíos. Éste no puede quedar disponible para el disfrute. Sólo Aguirre puede transgredir la ley quemando navíos y derramando vino, mientras para el resto no está permitido desobedecer la ley. Lo que en Aguirre es transgresión se transforma en mandato para sus súbditos, de este modo la perversión en Aguirre es un suplemento a la ley del Otro. A diferencia del banquete totémico, aquí derramar el vino es una forma de impedir que el resto de los marañones transgredan la ley. Es Aguirre el que se posiciona como el único con la posibilidad de transgredir y para que esto sea posible, debe resguardar que la ley pueda seguir existiendo. El vino debe ser eliminado en la medida que supone un resto, una fisura que debe ser devuelta. Aguirre, en tanto perverso, actúa como "un auxiliar de dios" (Lacan 2008: 231). Esta ambivalencia con respecto a la ley explica los adjetivos que se le han otorgado a Aguirre a lo largo de la historia, los que van desde ser el primer libertador de América, hasta constituir una figura execrable y demoníaca.

\section{Almesto y la NECESIDAD DE UN TESTIGO CÓMPLiCE}

Finalmente, con el objetivo de insistir en la estructuración perversa del relato más allá de la figura de Aguirre, debemos señalar la participación de Pedrarias de Almesto. Almesto no reviste relevancia sólo por el hecho de ser uno de los principales cronistas de la jornada, sino aún más por ser un testigo presencial y partícipe. Dicha importancia es evidente en el mismo relato ya que Almesto es la única persona que, ante la posibilidad y amenaza de ser asesinado por orden de Aguirre, es perdonado. Pedrarias, junto a otro soldado, decide huir de Aguirre, no obstante, el alcaide de la ciudad los atrapa y devuelve

${ }^{16}$ Según el texto "gesto" se refiere a la cara, lo ahorca porque le parece feo (Almesto 2012: 104). 
al tirano. Almesto dice que "allí hobo muchos que le rogaron que no matase al Pedrarias, y luego mandó hacer cuartos al Alarcón y perdonó al Pedrarias, cosa que con ninguno había fecho, de que quedaron todos muy espantados" (Almesto 2012: 106).

Baraibar, en su estudio preliminar, llama la atención sobre este hecho, mencionando que "carece de explicación lógica, teniendo en cuenta el proceder habitual del tirano" (en Almesto 2012: 26) siendo aquello la causa del 'espanto' de todos; esto motiva en Baraibar la comparación con otras versiones, incluida una segunda de Almesto. Vásquez confirma la inexplicable conducta de Aguirre: " "A éste quiero dejar vivo, y á ese otro hacedlo luego pedazos.» . . . cosa que es insólita, y que hasta allí el dicho tirano no habia usado con otro ninguno" (Vásquez 1881: 142). No obstante, Vásquez otorga una explicación omitida en el primer relato de Almesto, aún más sorprendente: "fué, cierto, la hija la que le rogó que no matase á Pedrarias, y que por su ruego lo hizo" (Vasquez 1881: 141). Ramírez de Arellano, editor del texto de Vásquez, también señala "la extraña é insólita clemencia que el feroz é implacable Lope de Aguirre usó para con el tal Pedrárias de Almesto... la bella hija del tirano fué el ángel salvador del prisionero" (Vásquez 1881:34), hipótesis considerada también por Baraibar (Almesto 2012: 27).

Sin embargo, por más que podamos explicar el perdón, sigue siendo inexplicable cómo es que Aguirre consintiese una relación con su hija. Ya hemos mencionado la centralidad que la hija posee para Aguirre, así también sabemos que Aguirre no tolera excepciones a una norma por parte de sus subalternos, ya que necesita suplementar la ley del Otro.

Es posible explorar una vía diferente de comprensión si atendemos a los tres papeles que Almesto juega en la jornada: partícipe, testigo y escribano, siendo éste último un rol muy particular. ¿̇s posible explicar el perdón y el romance, en definitiva, la excepcionalidad de la posición de Almesto desde su rol de escribano? ¿No es acaso mismo su rol de escribano un rol excepcional, un privilegio al que no todos pueden acudir? Baraibar señala, a partir de una relación anónima, que el perdón de Aguirre se explica porque Almesto "era buen escribano" (Almesto 2012: 27). De hecho, Pedrarias, único Bachiller en la expedición, "pudo haber hecho las veces de escribano durante la jornada, para Pedro de Orsúa, primero, y para Lope de Aguirre, después" (Almesto 2012: 17); por ello, es probable que también haya sido el cronista del breve principado de Guzmán. De esta forma llegamos a preguntarnos ¿Qué relación existe entre la escritura, el mito y la perversión?

Aguirre, encarnando la perversión, necesita de Pedrarias de Almesto, como si estuviese impelido a dejar huella y rastro de lo que va haciendo, pero también como si necesitase a un testigo para afrontar e intentar suplementar al Otro. Esto colinda con la necesidad de un testigo cómplice en la perversión, necesidad que es cubierta primariamente por la madre, quien es la espectadora privilegiada. Este cómplice es indispensable porque

Lo más importante para el perverso es siempre que el Otro esté suficientemente comprometido, inscripto en referencias conocidas, sobre todo de respetabilidad, para que cada nueva experiencia cumpla oficio de desenfreno, es decir, para que el 
Otro se vea extraído de su sistema, y para que acceda a un goce cuyo dominio, de todos modos, el perverso está seguro de tener (Dor 2000: 65).

Ese es el lugar de Almesto, en tanto escriba, como el otro que permite una posición exhibicionista. Siguiendo lo anterior, interpretamos la relación Aguirre-Almesto como una forma en que la perversión busca adentrarse al texto, dejar huella mediante la escritura como una inscripción transgresora. Aguirre traspone el límite de lo posible y en esa frontera sólo la escritura permite construir un parche a tamańa rasgadura de la realidad.

Es como si Aguirre escribiese su propia relación, tal como escribió la carta a Felipe II, usando a los escribas en un desafío ante la ley del Otro. ¿Dónde se encuentra mejor encarnizado el Otro que en el lenguaje y su estructura? ¿No es la escritura una forma de transgredir y suplementar al Otro? Según esta perspectiva, Aguirre es el propio escritor de la relación (consciente e inconscientemente) y los hechos van acompañados de esa mirada cómplice, cuyo vehículo es Almesto, testigo necesario, porque la lógica perversa desconfía de la presencia del gran Otro y quiere desestabilizarla una y otra vez. Almesto, como el testigo fundamental, afirma y sostiene el desafío, la burla y la transgresión durante toda la jornada y después de ella.

Frente a la personificación de la perversión en Aguirre, la cual se traslada a la estructura del relato mismo, Almesto viene a encarnar aquella posición neurótica de la cual necesita el perverso para instalar el desafío y la transgresión, y hacer así visible la devolución del objeto perdido. Otra forma de mirarlo sería recurriendo a los tres registros lacanianos, en donde el registro de lo Simbólico es figurado por Almesto a través de su labor de escritura e historización, y el registro de lo Real es invocado constantemente por Aguirre, obligándonos a observar horrorizados lo que está fuera del lenguaje y es inasimilable a la simbolización, es decir lo imposible (Evans 2007: 163). Almesto asume el desafío de inscribir simbólicamente este imposible, ya que lo Real no cesa de no escribirse (Chemama 1996: 372$)^{17}$.

En la figura de Almesto vemos de forma simbólica la relación de la literatura con la perversión. En este vínculo, se trata del ejercicio vivencial de volver tramitable lo abyecto que nos preexiste, tal como señala Julia Kristeva:

la experiencia de la falta misma como lógicamente anterior al ser y al objeto -al ser del objeto- entonces se comprende que su único significado sea la abyección, y con más razón la abyección de sí siendo su significante... la literatura (Kristeva 2006: 12).

\footnotetext{
${ }^{17}$ Por otro lado, Almesto también se mueve a través de los tres registros lacanianos: desde lo Real como partícipe, siendo incluso herido gravemente en el cuello debido a su huida; desde lo Imaginario como espectador o testigo de la transgresión, quien debe imaginarse como personaje dentro de su relato; y desde lo Simbólico como escribano, como autor de una ficción y como súbdito buscando la salvación, el perdón de la ley. En cuanto a esto último, la cicatriz de la herida opera como inscripción simbólica de lo Real, que le permite dar cuenta de su huida y rechazo frente a la rebelión.
} 
De esta manera, Almesto, mediante sus propias fantasías elabora las diversas abyecciones presentes en la jornada, pero también ficcionaliza desde su posición neurótica, desde la abyección de sí. Es este mismo proceder escritural el que le permite zafarse del juicio por su participación en la jornada. Este artificio en torno a su papel de escribano lo podemos apreciar en la reescritura de su propio papel en la jornada, lo que le permite ser un personaje dentro dentro de la trama y el conjunto de posiciones, todas estas en relación al poder ${ }^{18}$. La escritura es usada como una forma de burlar al poder, desde una posición privilegiada de quien tiene la potestad de ser el mediador de los signos entre lo que ocurrió en la jornada y las diversas instancias de la Ley: la monarquía, la iglesia y la burocracia colonial. Todo ello reinserta el movimiento paradojal u oscilante de la perversión: la escritura aparece tanto como vehículo de la perversión, como un saber al servicio de los poderes hegemónicos, es decir de la Ley.

\section{APRECIACIONES FinAles}

A lo largo de este recorrido hemos indagado en una nueva forma de comprensión de la relación de la jornada de Omagua y el Dorado escrita por Pedrarias de Almesto. Esta aproximación nos ha permitido ir más allá de un análisis de la figura de Lope de Aguirre desde sus rasgos o conductas, para pasar a la estructura del relato. Hemos recurrido al psicoanálisis freudiano y lacaniano como fuentes de conceptos para arribar a dos conclusiones; en primer lugar, el carácter mítico presente en la relación, dado por sus elementos trágicos, heroicos, corales, originarios, fundacionales y transgresores que han generado efectos indelebles en la historia y literatura colonial; en segundo lugar, el carácter perverso de la estructura del relato, coherente no solo con los rasgos de desafío y transgresión presentes en la figura de Aguirre, sino además con la oscilación o ambivalencia de la estructura perversa con respecto a la castración y en vinculación a las posiciones subjetivas ocupadas por otros personajes de la relación. Hemos incluso interpelado al propio Almesto en su rol de escribano y cómo esto se inserta en la vinculación entre literatura y perversión. De este modo, podemos afirmar que la Relación de Almesto nos habla de una mítica perversión.

El mito que hemos venido delineando no ocurre en un espacio vacío, éste encuentra su soporte en un territorio específico: América Latina. ¿Qué espacio sería más propicio para una tragedia como ésta? Creemos que la figura mítica de Lope de Aguirre es indisociable

\footnotetext{
${ }^{18}$ En este sentido podría ser interesante comparar de forma más detallada las dos relaciones escritas por Almesto, desde el lente analítico que proponemos. Mientras en la segunda relación, la inocencia de Almesto es argumentada desde procedimientos retóricos que acuden a un autoensalzamiento o autoapología (Almesto 2012: 24), lo cual busca cerrar u obturar posibles contradicciones narrativas; en la primera relación el papel de Almesto es mucho más confuso, quedando mucho más abierto a reinterpretaciones, Esto releva el papel del primer relato, no en términos de constituir una especie de registro 'original' u 'oficial', sino más bien entendiéndolo como una ficción en donde queda mucho más manifiesta la ambigüedad o complicidad de Almesto como testigo necesario en las diversas transgresiones a la Ley.
} 
del mayor genocidio conocido en la historia de la humanidad: la conquista de América. En su sangriento devenir también fueron transgredidas todas las instituciones humanas de los diversos pueblos aborígenes. De ahí que este relato, reescrito innumerables veces, sea una suerte de retazo de esos tiempos primordiales de nuestra identidad como habitantes de estas latitudes, una suerte de fragmento inconsciente que insiste en ser elaborado una y otra vez. La jornada de Omagua y el Dorado se imbrica con nuestras raíces coloniales. Su persistencia mítica nos interpela hasta al presente, en la medida en que la transgresión y la violencia colonial aún permanecen de diversas formas (Quijano 2009: 3-4).

¿Qué es lo que seduce del mito de Aguirre y cómo puede tener lecturas tan contrapuestas? Quizá se pueda aventurar una respuesta a esto, en términos de la ambigüedad constitutiva que encarna el perverso frente a la Ley, a las múltiples máscaras que envuelven el objeto $a$ y a la seducción que produce en nosotros, los neuróticos, fantasear con la transgresión de la Ley. Esta ambigüedad, como punto de anclaje de la perversión, permite entender que Lope de Aguirre se muestre como un Tirano, un Loco y un príncipe de la libertad, al mismo tiempo. Aunque frente a esto último debemos decir, de forma oblicua, como reverso, a la manera en que opera el psicoanálisis, que Aguirre está capturado por la Ley y no hay posibilidad de subversión bajo esta lógica.

Visto así, el mito perverso de Lope de Aguirre no sólo admitiría una nueva comprensión, sino también nos invitaría a cuestionar el privilegio que el mito de Edipo ha tenido desde el psicoanálisis para la comprensión de nuestra historia humana. Si el mito de Aguirre abre la posibilidad de comprender la lógica de subjetivación y aculturación subyacente al proceso de Conquista, quizá debamos reproblematizar el estatuto edípico de nuestro pasado continental y descentrar la hegemonía que la estructura neurótica ha tenido como matriz de análisis, cuestionando así los lugares comunes de la teoría psicoanalítica. Quizá nuestro pasado latinoamericano es más aguírrico que edípico, más perverso que neurótico. ¿De qué otros modos la teoría psicoanalítica podría ser interpelada por nuestro pasado? ${ }^{19}$

\footnotetext{
${ }^{19}$ El psicoanálisis debería ser cuestionado en torno a la especificidad colonial, el sur tiene otro origen, donde la transgresión generalizada es una matriz identitaria: "Mientras en la guerra hay violación corporal y muerte, en el infierno del mundo colonial la muerte y la violación ocurren como realidades y amenazas diarias. Mortandad y violación corporal están inscritas en las imágenes de los cuerpos coloniales" (Maldonado 2007: 148). Por otra parte, la faz mítica de Aguirre nos habla de una ambivalencia constitutiva de las identidades de élites nacionales en América: "una conciencia "autodeclarada 'mestiza' cuando desea defender sus posesiones nacionales frente al otro metropolitano y pretendidamente 'blanca' cuando quiere diferenciarse de aquellos a quienes despoja en esos territorios" (Palermo \& Quintero 2014: 29). Además, esta ambivalencia se podría relacionar con el llamado 'entre-lugar' del discurso latinoamericano (Santiago 2000). Así también, la estructura perversa puede ser relevada como una clave interpretativa de nuestros procesos de mestizaje, atendiendo al lugar de la mujer en la colonia: "La china, la mestiza, la pobre, continuó siendo ese 'obscuro objeto del deseo' de los hombres; era ella quien 'iniciaba' a los hijos de la familia en la vida sexual; pero también era la suplantadora de la madre, en su calidad de 'nana' (niñera). China-madre y china-sexo se conjuntaron para reproducir la alegoría madre/ hijo de las constituciones genéricas en nuestro país. En el mundo inquilino, la imagen del hacendado como el "perverso trascendental" (Morandé 1980), es decir como el fundador del orden, lo hacía poseer el derecho de procrear huachos en las hijas, hermanas y mujeres de los campesinos adscritos a su tierra. Así, numerosos vástagos huérfanos poblaron el campo con una identidad confusa" (Montecino 1991: 55-56).
} 
Llegado a este punto podemos comprender el porqué de la finitud y destino trágico de la jornada, ya que, si bien la perversión transgrede, nunca llega a ser una subversión del orden, es una transgresión que legitima, hace visible la Ley, coloca en un nicho al gran Otro. Como lo señaló Lacan: "père versión: dos palabras, de las cuales père es padre. Diríamos: hacia el padre, una vuelta al padre, un llamado al padre, lo que recuerda que la perversión en ningún sentido es una subversión" (Miller 2001: 17). Esta vuelta al padre, se liga con la primera transgresión de la cual hablábamos con respecto al mito de la horda primordial. Quizá por ello, en términos políticos, la jornada no podría haber terminado en la liberación de América, en un proyecto alternativo independentista, porque se trataba de clamar, hacer aparecer, volver al padre, al rey y también a Dios. Aguirre y los marañones, más que mostrar la Ira de este Dios, se vuelven "un auxiliar de dios" (Lacan 2008: 231). Si en Hamlet se trata de la aparición y palabras del espectro del padre, creemos que en el caso del mito trágico de Aguirre se trata de un espectro silente y hecho de paja, el cual se asesina para volver a reencarnar.

En este cierre nos permitimos algunas preguntas: ¿es posible una organización sin ocupar el lugar vacío del Padre? ¿Y cómo no caer en el terror luego de su destitución? ¿En qué medida aún asistimos a la política de señores y señoras fechas de paja? Queda abierta la posibilidad de tomar la estructuración perversa en términos políticos, como una forma de seguir elaborando este mito colonial sobre nuestro pasado latinoamericano.

\section{Obras Citadas}

Almesto, Pedrarias de. 2012. Relación de la jornada de Omagua y el Dorado. Ed. Álvaro Baraibar. New York: IDEA/IGAS.

André, Serge. 1995. La impostura perversa. Madrid: Paidós.

Anónimo. 2010. Relación de todo lo sucedido en la gobernación de Omanga, Ed. B. Pastor y S. Callau, Madrid: Castalia. 323-339.

Armas, Ingrid de. 1988. "Lope de Aguirre, el doble mito: Tirano o príncipe de la libertad". América: Cahiers du CRICCAL 1: 141-169.

Baraibar, Álvaro. 2011. "Lope de Aguirre: La construcción de una imagen del poder". Alpha 33: $187-200$.

Bettelheim, Bruno. 1977. Psicoanálisis de los cuentos de hadas. Barcelona: Crítica.

Butler, Judith; Ernesto Laclau \& Slavoj Žižek. 2011. Contingencia, hegemonía y universalidad, diálogos contemporáneos en la izquierda. Buenos Aires: Fondo de Cultura Económica.

Castoriadis, Cornelius. 2004. Sujeto y verdad en el mundo histórico-social, seminarios 19861987. La creación humana I. Buenos Aires: Fondo de Cultura Económica.

Chemama, Roland. 1996. Diccionario del psicoanálisis. Diccionario actual de los significantes, conceptos y matemas del psicoanálisis. Buenos Aires: Amorrortu.

Díez Torres, Julián. 2011. "Los marañones y la polémica de la conquista: retórica e ideas políticas en la carta de Lope de Aguirre a Felipe II". Alpha 33: 201-214.

Dor, Joël. 2008. El padre y su función en psicoanálisis. Buenos aires: Nueva Visión. 
2000. Estructuras clinicas y psicoanálisis. Buenos Aires: Amorrortu.

1995. Estructura y perversiones. Barcelona: Gedisa.

Eliade, Mircea. 1991. Mito y realidad. Barcelona: Labor.

Evans, Dylan. 2007. Diccionario introductorio de psicoanálisis lacaniano. Buenos Aires: Paidós.

Freud, Sigmund. 1984. V, La interpretación de los sueños (parte 2) (1900-1901). Buenos

Aires: Amorrortu.

. 1986a. XIII, Tótem y tabú y otras obras (1913-1914). Buenos aires: Amorrortu.

. 1986b. XVII, De la historia de una neurosis infantil (el <<Hombre de los Lobos >>)

(1917-1919). Buenos Aires: Amorrortu.

. 1992a. XVIII, Más allá del principio de placer. Psicología de las masas y análisis del yo y otras obras (1920-1922). Buenos Aires: Amorrortu.

. 1992b. XXI, El porvenir de una ilusión, El malestar en la cultura y otras obras (19271931). Buenos aires: Amorrortu.

Galeano, Eduardo. 1982. Memoria del fuego (I). Los nacimientos. Madrid-México: Rebelión.

Galster, Ingrid. 2011. Aguirre o la posteridad Arbitraria. La rebelión del conquistador vasco Lope de Aguirre en historiografía y ficción histórica (1561-1992). Bogotá: Editorial Universidad del Rosario.

Herzog, Werner. 1972. Aguirre der zorn gottes. Alemania del Oeste (RFA): Werner Herzog Filmproduktion.

Julien, Philippe. 2012. Psicosis, perversión, neurosis. Buenos Aires: Amorrortu.

Kristeva, Julia. 2006. Poderes de la Perversión. México: Siglo XXI.

Lacan, Jacques. 2008. XVI, El seminario. De un Otro al otro. Buenos Aires: Paidós. . 2005. Escritos, tomo 1. Buenos Aires: Siglo XXI.

Laclau, Ernesto. 2000. Nuevas reflexiones sobre la revolución de nuestro tiempo. Buenos Aires: Nueva Visión.

Lastres, Juan \& Alberto Seguín. 1942. Lope de Aguirre, el rebelde. Estudio histórico-psicológico. Monografía. Lima: Comité pro IV Centenario del Amazonas, Ministerio de Relaciones Exteriores de Perú.

Leal, Alejandra. 2010. "Ritual de Salvación centrado en la crónica de la jornada de Omagua y El Dorado”. Atenea 501: 35-52.

Maldonado-Torres, Nelson. 2007. "Sobre la colonialidad del ser: contribuciones al desarrollo de un concepto”. En: Castro-Gómez, Santiago \& Ramón Grosfoguel. Eds. El giro decolonial. Reflexiones para una diversidad epistémica más allá del capitalismo global. Bogotá: Siglo del Hombre Editores. 127-168.

Marcus, Raymond. 1968. "El mito literario de Lope de Aguirre en España y en Hispanoamérica”. AIH. Actas III: 581-592.

Miller, Jacques-Alain. 2001. "Fundamentos de la Perversión". En: Miller, Jacques-Alain et al. Perversidades. Buenos Aires: EOL-Paidós. 15-38.

Montecino, Sonia. 1991. Madres y huachos. Alegorias del mestizaje chileno. Santiago de Chile: Editorial Cuarto Propio.

Nasio, Juan David. 1992. Cinco lecciones sobre la teoría de Jacques Lacan. Barcelona: Gedisa. 
Neira, Hernán, Juan Fierro \& Fernando Viveros. 2006. "Lope de Aguirre: elementos para una teoría del mito de la Conquista”. Estudios Filológicos 41: 145-163.

Palermo, Zulma \& Pablo Quintero. 2014. Aníbal Quijano. Textos de fundación. Buenos Aires: Ediciones del signo.

Pardal, Ramón. 1934. "El delirio de reivindicación en un conquistador de América. El caso de Lope de Aguirre, 'El peregrino"”. Conferencias 2 (8): 8-18.

Pardo F., Miriam. 2006. "La perversión como estructura”. Limite 1 (13): 169-193.

Posse, Abel. 1978. Daimón. Barcelona: EC.

Quijano, Aníbal. 2009. "Colonialidad del Poder y Des/colonialidad del Poder”. XXVII Congreso de la asociación Latinoamericana de Sociología. Buenos Aires. 1-15.

Rostagnotto, Alejandro \& Mariela Yesuron. 2014. "El estudio de la perversión en Lacan”. VI Congreso Internacional de Investigación y Práctica Profesional en Psicología XXI Jornadas de Investigación Décimo Encuentro de Investigadores en Psicología del MERCOSUR. Facultad de Psicología - Universidad de Buenos Aires, Buenos Aires.

Rostagnotto, Alejandro \& Mariela Yesuron. 2015. "Instrumento de goce: perversión”. VII Congreso Internacional De Investigación y Práctica Profesional en Psicología. XXII Jornadas de Investigación. XI Encuentro de Investigadores en Psicología del MERCOSUR. Facultad de Psicología - Universidad de Buenos Aires, Buenos Aires.

Rostagnotto, Alejandro \& Mariela Yesuron. 2016. "Clínica lacaniana de la perversión". Anuario de Investigaciones 23: 187-193.

Santiago, Silviano. 2000. El entrelugar en el discurso latinoamericano. En: Amante, Adriana \& Florencia Garramuño (selección, traducción y prólogo). Absurdo Brasil. Polémicas en la cultura brasileña. Buenos Aires: Biblos.

Saura, Carlos. 1988. El Dorado. Madrid: Compañía Iberoamericana de TV.

Silva, Miguel Otero. 1985. Casas Muertas y Lope de Aguirre Principe de la libertad. Caracas: Biblioteca Ayacucho.

Triviños, Gilberto. 1991. Ramón J. Sender. Mito y contramito de Lope de Aguirre. Zaragoza: Institución Fernando el Católico.

Vásquez, Francisco. 1881. Relación de todo lo que sucedió en la jornada de Omagua y Dorado hecha por el gobernador Pedro de Orsúa. Ed. Feliciano Ramírez de Arellano, Marqués de la Fuensanta del Valle. Madrid: Sociedad de Bibliófilos Españoles.

Yesuron, Mariela \& Alejandro Rostagnotto. 2015. "La categoría clínica de la perversión y su diagnóstico desde el psicoanálisis lacaniano”. VII Congreso Internacional De Investigación y Práctica Profesional en Psicología. XXII Jornadas de Investigación. XI Encuentro de Investigadores en Psicología del MERCOSUR. Buenos Aires: Facultad de Psicología - Universidad de Buenos Aires.

Žižek, Slavoj. 2003 “The matrix o las dos caras de la perversión”. Desde el Jardín de Freud 3: 292-307. . 2016. El sublime objeto de la ideología. Buenos Aires: Siglo XXI. 